\title{
BAHASA GURU DALAM MENGEKSPRESIKAN PENGHARGAAN (REWARD) DAN HUKUMAN (PUNISHMENT) KEPADA SISWA DI TAMAN KANAK-KANAK (TK ) AISYIYAH IV KOTA BENGKULU
}

\begin{abstract}
Asparida
Abstract

This study aims to determine the teachers' use of language in expressing appreciation and punishment in Kindergarten (TK) Aisyiyah IV Bengkulu City. The theory is used with respect to theories of language teachers, the theory of appreciation, and the theory of punishment. The method used in this study is a qualitative descriptive method. With the source data comes from the learning activities undertaken by teachers and students in kindergarten classes B-1 and B-3 IV Aisyiyah city of Bengkulu with data in the form of language teachers in learning activities obtained from the recording. Data collection techniques using the recording techniques. Then, data analysis techniques with the following steps: (a) transcription, (b) identification, (c) reduction, (d) coding and classification, (e) interpretation, and (f) conclusion. The study suggests that teachers in TK Aisyiyah IV Bengkulu award by 28 dialog (51.85\%) in Teaching and Learning Activities (KBM) in the Class $B-1$ from a total of 54 teachers dialog. While the teaching in the class B-3 teachers awarded the dialogue as much as 22 (30.55\%) of the number of teachers is 72 dialog dialog. Both of KBM in the Class B-1 as well as teaching at the Class B-3, overall teacher award in the form of praise. Forms of teacher praise given the form of words: children pious, smart kid, smart, dear, industrious boy, the son of a quick, great kids, correct, and neat. Then, in giving punishment (punishment) there are 4 dialog teachers (0.74\%) in Teaching and Learning Activities (KBM) in the Class B-1 of the overall total of 54 teachers dialog dialog. Whereas the KBM in Class B-3, the teacher punishes the dialogue as much as $13(1.80 \%)$ of the overall dialogue sebayak 72 teacher dialogue. Punishment by teachers, both in the Class $B-1$ and the Class B-3 as a whole in the form of preventive punishment in the form of advice and words of command and the contents of the advice, such as the use of the phrase should not, take turns speaking, no, not a pious child, should see the teacher, should not break, should not eat, repeat attached, should not be throwing, and should not be saying nasty.
\end{abstract}

Key words: language teachers, appreciation, punishment.

\section{A. PENDAHULUAN}

Bahasa merupakan alat komunikasi yang sangat penting bagi manusia. Dengan bahasa kita mampu menyampaikan informasi yang kita harapkan kepada seseorang. Dalam arti, semakin baik bahasa seseorang, maka semakin mudah ia memperoleh tujuan yang ia inginkan lewat bahasanya. Begitupun seorang guru, yang sebagian besar mengandalkan bahasa dalam menyampaikan materi.Guru yang profesional hendaknya memiliki kemampuan bahasa yang baik dan benar. Bahasa guru yang baik dan benar ditunjukkan dengan penggunaan bahasa yang baku, komunikatif, dan memiliki sopan santun dalam berbahasa. Hal ini dikarenakan materi yang disampaikan menggunakan bahasa baik lisan maupun tulisan yang apabila informasi berupa materi tersebut disampaikan dengan bahasa yang baik maka siswa akan menerima dengan baik juga materi tersebut. 
Salah satu penggunaan bahasa guru yang penting diterapkan dalam proses pembelajaran adalah bahasa penghargaan dan bahasa hukuman. Bahasa penghargaan adalah berbagai bentuk apresiasi atau penghargaan terhadap suatu prestasi yang telah dicapai oleh suatu atau sekelompok anak dalam aktivitas tertentu. Penghargaan dapat mendorong dan memberi motivasi kepada anak untuk lebih berprestasi, namun sampai dewasa ini masih terdapat banyak orang tua atau guru yang beranggapan bahwa penghargaan seperti pemberian hadiah tidak penting, dengan alasan bahwa sewajarnya anak berperilaku demikian dan berprestasi sesuai dengan kemampuannya. Kemudian, hadiah juga justru akan melemahkan motivasi anak untuk melakukan sesuatu yang memang seharusnya mereka lakukan.

Sedangkan hukuman merupakan reinforcement yang negatif, tetapi kalau diberikan secara tepat dan bijak bisa menjadi alat motivasi. reward dan punishment digunakan sebagai instrument untuk membangkitkan semangat atau motivasi siswa agar semakin giat dalam belajar sehingga tujuan pendidikan dapat dicapai, namun para pendidik hendaknya mempertimbangkan bagaimana reward dan punishment itu diberikan secara bijak yang diungkapkan dalam bahasa lisan seorang guru. Khususnya pengajaran di tingkat TK para siswa harus lebih diberikan apresiasi berupa hadiah dan hukuman yang sifatnya menyenangkan. Hal ini dikarenakan pada usia TK, para siswa melakukan hal-hal yang menghambat jalannya proses pembelajaran, seperti menangis dan lainnya. Begitu pentingnya pemberian penghargaan dan hukuman dalam proses pembelajaran di tingkat TK karena mampu memberikan motivasi belajar yang kuat kepada siswa sehingga temuan belajar siswa akan tercapai dengan baik. Selama menjadi pengajar di TK, penulis melihat para guru mengguna-kan penghargaan dan sedikit sekali memberikan hukuman, tetapi sebagian siswa ada yang belum memiliki motivasi yang besar dalam mengikuti kegiatan pembelajaran. Hal ini membuat penulis melakukan observasi awal pada semua kelas di TK Aisyiyah IV Kota Bengkulu khususnya terhadap penggunaan bahasa guru dalam proses pembelajaran. Temuan observasi awal ini memberikan informasi yang sama dengan pengalaman penulis mengajar bahwa para guru sudah memberikan penghargaan yang cukup baik dalam bentuk lisan seperti kata "anak-anak semuanya pintar" dan bentuk hukumanseperti, bernyanyi dan menirukan gaya tokoh idola, akan tetapi memang para siswa masih belum semuanya termotivasi untuk belajar dan mengikuti setiap aktivitas yang diberikan oleh guru

Dari Temuan observasi awal tersebut yang dilakukan penulis dengan meninjau langsung ke beberapa kelas di TK Aisyiyah IV Kota Bengkulu, mengenai pemberian penghargaan dan hukuman, diperoleh gambaran bahwa pemberian penghargaan dan hukuman tersebut belum memberi-kan dampak positif bagi semua siswa terutama dalam meningkaTK an motivasi belajar dan temuan belajar sehingga perlu dilakukan penelitian tentang proses dan bentuk sebenarnya bahasa guru dalam memberikan penghargaan dan hukuman dalam proses pembelajaran. Oleh karena 
itu dirumuskan masalah; (1) bagaimana bahasa guru dalam mengekspresikan penghargaan (reward) diTK Aisyiyah IV Kota Bengkulu?, dan (2) bagaimana bahasa guru dalam mengekspresikan hukuman (punishment) di TK Aisyiyah IV Kota Bengkulu? Rumusan masalah tersebut akan mendeskripsikan tujuan penelitian; (1) bahasa guru dalam mengekspresikan penghargaan (reward) diTK Aisyiyah IV Kota Bengkulu, dan (2) bahasa guru dalam mengekspresikan hukuman (punishment) diTK Aisyiyah IV Kota Bengkulu.

Metode Penelitian yang digunakan dalam menjawab rumusan masalah penelitian ini adalah jenis metode deskriptif kualitatif. Data penelitian berupa uajran guru dalam kegiatan pembelajaran. Analisis data yang digunakan adalah; (1) transkripsi, (2) identifikasi, (3) reduksi data, (4) klasifikasi, dan (5) interpretasi dan menyimpulkan.

\section{Pembahasan}

Guru memberikan penghargaan dan hukuman, baik pada Kegiatan Belajar Mengajar (KBM) di Kelas B-1, maupun pada KBM di Kelas B-3. Akan tetapi, pemberian penghargaanmemang lebih banyak dibandingkan dengan pemberian hukuman. Hal ini bertujuan agar siswa lebih termotivasi belajar tanpa paksaan. Di samping itu, dampak yang kurang baik ditimbulkan pada saat KBM dari efek bahasa hukuman, misalnya: sikap siswa yang melawan, tidak menghargai guru ketika berbicara, memiliki sifat dendam, dan liannya.

Berkenaan dengan bentuk penghargaan dan hukuman memang hanya sebatas penghargaan dalam bentuk pujian, sedangkan hukuman hanya dalam bentuk anjuran dan perintah. Hal ini dikarenakan penelitian ini baru difokuskan pada dua KBM di dua kelas dengan masing-masing hanya satu kali pertemuan yang dianalisis dari Temuan rekaman bahasa guru, namun temuan ini sudah memberikan gambaran umum tentang bagaimana bahasa guru di TK Aisyiyah IV Kota dalam memberikan penghargaan dan hukuman. Walaupun berdasarkan pengamatan yang sudah dilakukan selama satu semester atau satu tahun pembelajaran, maka dapat disampaikan bahwa para guru memberikan penghargaan dalam bentuk hadiah (buku dan pena atau dalam bentuk barang lainnya), tetapi pada waktu tertentu seperti pada pembagian rapor, pemberian hadiah dalam bentuk barang berupa piala khusus pada waktu perlombaan mewarnai atau perlombaan lainnya. Penghargaan jenis lainnya pun juga dilakukan para guru, seperti dengan gerakan tepuk tangan, ancungan jempol, tetapi hal ini jarang sekali dilakukan oleh sebagian besar guru. Kemudian, untuk pemberian hukuman para guru di TK Aisyiyah IV Kota Bengkulu hanya sebatas hukuman dalam bentuk anjuran dan perintah hal ini ditunjukkan dari Temuan analisis bahasa guru di Kelas B-1 dan Kelas B-3.

Pemberian penghargaan dalam dua kegiatan pembelajaran di Kelas B-1 dan Kelas B-3 terjadi hampir pada setiap data dan secara keseluruhan guru memberikan penghargaan dalam bentuk pujian. Bentuk pujian yang diberikan guru berupa kata-kata: anak soleh, anak pintar, pintar, sayang, anak rajin, anak cepat, anak hebat, benar, dan rapi. Bentuk pujian ini sesuai dengan pendapat Indrakusuma (1973:159-161) bahwa dalam penghargaan yang 
diberikan kepada siswa bentuknya bermacam-macam, secara garis besar penghargaan dapat dibedakan menjadi empat macam, salah satunya yaitu pujian. Pujian menurut Indrakusuma sebagai satu bentuk penghargaan (reward) yang paling mudah dilakukan. Pujian dapat berupa kata-kata seperti: baik, bagus, bagus sekali, dan sebagainya, tetapi dapat juga berupa kata-kata yang bersifat sugesti.

Dengan kata-kata sugesti yang bersifat positif tersebut diharapkan mampu mengembangkan motivasi siswa dalam belajar. Akan tetapi, dari pemberian penghargaan tersebut, para guru belum sepenuhnya memberikan penghargaan yang memberikan nilai motivasi yang tinggi karena para guru ketika mengujarkan kata-kata pujian tersebut tidak terlihat siswa melakukan hal-hal yang termasuk ke dalam kriteria kata-kata pujian tersebut. Misalnya kata baik, guru ketika mengujarkan kata baik tidak dibarengi dengan siswa yang baik karena duduk manis atau baik karena pekerjaannya dikerjakan dengan cepat. Contoh lainnya seperti penggunaan kata anak pintar, para guru di TK Aisyiyah IV Kota Bengkulu juga memberikan pujian tersebut ketika siswa belum disebut siswa yang pintar, kata-kata pintar diberikan hanya sebagai perkataan agar siswa pintar bukan siswa melakukan kegiatan yang menunjukkan pintar, misalnya Budi, gambar yang kamu warnai sesuai dengan gambar yang sebernarnya. Benar-benar pintar kamu ya! Kalimat seperti ini belum terlihat dilakukan para guru di TK Aisyiyah IV Kota Bengkulu. Untuk melihat informasi yang sesungguhnya dapat dilihat dari contoh sebagai berikut:

PP99-G : Ya pinter, Feri diwarnain ya! Ya pinter Feri ya, ya diterusin! Eh,
Indri sama Diva, bikin ini ya sayang ya. Anak soleh, duduk sayang, anak soleh di sini, ya sebentar sayang. Ya, udah siap ya! Anak soleh, ya kayak gini ya bikinnya! Tau nggak bikinnya, tadi pertama tangkainya. Daunnya, terus warna apa lagi Icha? Ya, terus biru lagi! Ya, jadi warna birunya, terus, ya, Icha lanjutin ya! Sampai penuh ya kertasnya ica! Eh, yang ini sudah belum yang ini sayang?

PS100-S : Kami udem, kami udem galo. (kami sudah, kami sudah semua)

Contoh data 2 tersebut terjadi pada waktu guru dan siswa melakukan kegiatan mewarnai di Kelas B-1. Dari data ini terlihat pemakaian bahasa guru pada KBM di Kelas B-1 berupa penghargaan (reward) dengan hadirnya kata pintar dan anak soleh. Penghargaan lewat kata-kata tersebut belum menunjukkan kriteria siswa pintar dan siswa soleh. Sebaiknya sebagai guru ketika memberikan penghargaan (reward) harus menyajikan bahasa yang bermakna sebab, bila siswa pintar mengapa? Dan bila siswa soleh, karena apa?. Dialog guru tersebut dapat diubah menjadi seperti berikut.

PP99-G : Feri, warna yang kamu buat sangat indah. Pintar kamu ya!, Indri dan Diva, wah kalian duduknya rapi ya, soleh kalian ya.

Dari contoh perbaikan di atas, sebagai siswa akan merasa dihargai dengan pujian yang diberikan karena mereka telah melakukan hal yang menunjukkan anak pintar dan anak soleh. Selain itu, siswa yang lain akan mencontoh perilaku siswa yang diberi pujian tersebut karena sifatnya nyata sehingga semua siswa akan melakukan hal yang sama yaitu menjadi anak yang pintar dan soleh. Hal ini penting 
dilakukan karena siswa TK adalah siswa yang berada pada masa meniru, semakin banyak diberikan contoh yang baik, mereka akan membentuk pribadi yang baik, sebaliknya jika diberikan contoh yang buruk maka siswa tersebut akan terbentuk karakter yang buruk.

Dari pemberian penghargaan tersebut, jelas bahwa guru di TK Aisyiyah IV Kota Bengkulu berusaha memaksimalkan profesionalisme mengajarnya lewat bahasa penghargaan dalam bentuk pujian, tetapi pujian yang diberikan belum bersifat nyata terhadap pemahaman siswa belajar. Dalam memberikan pujian kepada siswa tersebut sudah memberikan dampak positif terhadap siswa yaitu mereka semangat belajar dan mengikuti setiap aktivitas belajar dengan baik. Hal ini dapat ditunjukkan dengan sebagian besar dari pujian yang diberikan, para siswa memberikan jawaban yang menyatakan mereka senang dan mampu melakukan setiap aktivitas belajar tentunya dengan bimbingan guru. Pernyataan senang dan mampu ini dapat dilihat dengan adanya jawaban siswa dengan kata-kata, siap, sudah bu, dan jawaban lainnya yang mempunyai makna bahwa siswa aktif dalam kegiatan belajar. Akan lebih baiknya, guru memberikan penghargaan dalam bentuk pujian yang sifatnya nyata atas tindakan siswa yang baik, pintar, dan soleh sehingga siswa lain mencontoh perilaku siswa yang baik tersebut.

Dalam hal pemberian hukuman (punishment) memang intensitasnya sangat sedikit dibandingkan dengan pemberian penghargaan, baik pada kegiatan pembelajaran di Kelas B-1 maupun pada kegiatan pembelajaran di Kelas B-3. Pemberian hukuman oleh guru, baik di Kelas B-1 maupun di Kelas B-3 secara keseluruhan berupa punishment preventif dalam bentuk anjuran dan perintah dan berupa perkataan yang isinya nasihat, seperti dengan penggunaan frase tidak boleh, bergantian berbicara, jangan, bukan anak soleh, harus lihat ibu guru, tidak boleh istirahat, tidak boleh makan, mengulang menempel, tidak boleh melempar, dan tidak boleh berkata jorok.

Penggunaan bahasa hukuman oleh guru di TK Aisyiyah IV Kota Bengkulu dalam bentuk anjuran dan perintah dapat dicontohkan dari sebagian besar dialog guru menggunakan kalimat sebagai berikut:

(1) Anak soleh, nggak boleh ngomongnya kayak gitu.

(2) Gentian ngomongnya, coba duduk di sana semua, ibu mau jelasin ni. dan

(3) Siapa yang mau istirahat, duduk yang rapi, pungut nak, masukan kacangnya nak, kelasnya sudah tidak berantakan baru istirahat, udah? Semuanya udah?.

Hal ini sesuai dengan pendapat Purwanto (2006:189) bahwa tujuan pemberian hukuman adalah menjaga agar hal-hal yang dapat menghambat atau mengganggu proses pendidikan bisa dihindarkan.

Dari uraian mengenai pemberian hukuman tersebut, dapat disimpulkan bahwa pemberian hukuman oleh guru di TK Aisyiyah IV Kota Bengkulu masih dalam bentuk perkataan berupa anjuran dan perintah. Anjuran dan perintah yang diberikan oleh guru sudah cukup baik karena ketika mengucapkan-nya guru sudah memberikan alasan terhadap anjuran dan perintah yang diberikan kepada siswa sehingga siswa tidak melakukan hal-hal yang dianjurkan atau dilarang tersebut.

Dalam hal pemberian hukuman guru terlihat sangat sedikit dan 
menghindari pemberian hukuman kepada siswa karena bila diberikan secara terus-menerus siswa akan merasa terkekang oleh aturan yang ada dan mencari cara agar siswa tersebut terbebas dari hukuman yang pada akhirnya siswa akan memberontak dan tidak mau lagi belajar. Hal ini sesuai dengan pendapat Skinner (dalam Brown, 2007) yang kurang setuju dengan metode hukuman karena dapat mengakibatkan beberapa hal sebagai berikut: (a) perubah-an perilaku sangat bersifat sementara, (b) dampak psikologis yang buruk mungkin terjadi akan terkondisi (menjadi bagian dari jiwa si terhukum), dan (c) hukuman mendorong si terhukum mencari cara lain (meskipun salah dan buruk).

\section{Simpulan}

Bahasa guru dalam memberikan penghargaan, baik di Kelas B-1 maupun di Kelas B-3 TK Aisyiyah IV Kota Bengkulu secara keseluruhan dalam bentuk pujian. Bentuk pujian yang diberikan guru berupa kata-kata: anak soleh, anak pintar, pintar, sayang, anak rajin, anak cepat, anak hebat, benar, dan rapi. Pemberian penghargaan lewat kata-kata pujian tersebut belum seluruhnya menunjukkan penghargaan yang langsung dan nyata terhadap prestasi atau temuan pekerjaan diperoleh siswa sehingga siswa belum merasa dihargai atas Temuan pekerjaan atau prestasi mereka. Bahasa guru dalam memberikan hukuman di TK Aisyiyah IV Kota Bengkulu baik di Kelas B-1 maupun di Kelas B-3 secara keseluruhan berupa punishment preventif dalam bentuk anjuran, perintah, dan perkataan yang isinya nasihat, seperti dengan penggunaan frase tidak boleh, bergantian berbicara, jangan, bukan anak soleh, harus lihat ibu guru, tidak boleh istirahat, tidak boleh makan, mengulang menempel, tidak boleh melempar, dan tidak boleh berkata jorok. Hukuman yang diberikan sifatnya sudah langsung dan nyata terhadap perilaku siswa yang tidak sesuai dengan harapan pendidikan. Para siswa akan merasa tidak nyaman ketika melakukan hal yang telah dianjurkan dan diperintahkan guru tersebut.

Pemberian penghargaan oleh guru di TK Aisyiyah IV Kota Bengkulu, penggunaannya lebih banyak dibandingkan dengan pemberian hukuman dalam proses pembelajaran.

\section{Saran}

Beberapa saran dari temuan penelitian ini yaitu: (1) penelitian ini hanya sebatas pada duaKegiatan Belajar Mengajar (KBM) yaitu satu pertemuan di Kelas B-1 dan satu pertemuan di kelas B3 sehingga belum ditemukan semua bentuk penghargaan dan hukuman yang dilakukan oleh guru TK Aisyiyah IV Kota Bengkulu sehingga peneliti lain dapat melanjutkan penelitian pada jenjang waktu yang dapat memperlihatkan semua bentuk penghargaan dan hukuman, misalnya dalam satu semester atau satu tahun pembelajaran; (2) penelitian ini menggambarkan penggunaan bahasa guru berupa penghargaan (reward) dan hukuman (punishment) yang dapat dijadikan bahan perbaikan bagi para guru TK Aisyiyah IV Kota Bengkulu khususnya dan bagi guru pada tingkat TK pada umumnya; (3) hendaknya para guru lebih memperbanyak pemberian penghargaan dalam proses pembelajaran dan hindari seminimal mungkin pemberian 
hukuman; dan (4) penghargaan yang diberikan baiknya jangan membuat para siswa terpaksa dalam melakukan aktivitas pembelajaran.

\section{Daftar Pustaka}

Arikunto, Suharsimi. 2006. Prosedur Penelitian; Suatu Pendekatan \& Praktek. Jakarta: Rineka Cipta.

Aslinda, dan Syafyahya, Leni. 2007. Pengantar Linguistik. Bandung: Refika Aditama.

Brown, Douglas,H. 2007. Prinsip Pembelajaran dan Pengajaran Bahasa (terj. Noor Cholis dan Avianto Pareanom). Jakarta: Pearson Education.

Chaer, Abdul. 2003. Psikolinguistik Kajian Teori. Jakarta: PT Rineka Cipta.

Depdiknas. 2006. Kurikulum 2004 Standar Kompetensi: Taman Kanak-Kanak dan Raudlatulathfal. Jakarta: Depdiknas.

Moleong, Lexy J. 2006. Metodologi Penelitian Kualitatif Edisi Revisi. CV Bandung: PT Remaja Rosdakarya.
Pasya, Hasan Syamsi. 2010. Ibu, Bimbing Aku Menjadi Anak Soleh. Jakarta: Pustaka Rahmat.

Purwanto. M. Ngalim. 2004. Psikologi Pendidikan. Bandung: PT Remaja Rosdakarya Offset.

Chaer, Abdul. 2007. Linguistik Umum. Jakarta: Rineka Cipta.

Purwanto. M. Ngalim. 2007. Ilmu Pendidikan Teoritis dan Praktis. Bandung: PT Remaja Rosdakarya Offset.

Sugiono. 2009. Metode Penelitian Kuantitatif Kualitatif dan R\&D. Bandung: alfabeta.

Sujiono, Yuliana Nurani. 2011. Konsep Dasar Anak Usia Dini. Jakarta; PT Indeks.

Suratno. 2005. Pengembangan Kreativitas Anak Usia Dini. Jakarta; Departemen Pendidikan Nasional.

Wijanarko, Jarot. 2010. Mendidik Anak. Jakarta: Suara Pemulihan.

Yamin, Martinis. 2011. Paradigma Baru Pembelajaran. Jakarta: Gaung Persada (GP) Press. 